\title{
Assessment of performance and student feedback in the flipped classroom
}

\section{Dr. Jean-Michel I. Maarek, University of Southern California}

Jean-Michel Maarek is associate professor of engineering practice and director of undergraduate affairs in the Department of Biomedical Engineering at the University of Southern California. His educational interested include engaged learning, student assessment, and innovative laboratories

\section{Brittany Kay, University of Southern California}

Brittany Kay is a full-time lecturer in the Biomedical Engineering department of the University of Southern California, teaching both graduate and undergraduate courses. She received her B.S. (2006), M.S. (2012), and Ph.D. (2012) in the field of Biomedical Engineering from the University of Southern California, focusing on pharmacokinetic/pharmacodynamic modeling during her graduate career. 


\section{Assessment of performance and student feedback in the flipped classroom}

\section{Background:}

The flipped classroom approach inverts the traditional "teaching/lecture - learning/homework" model by presenting the course content outside of classroom ahead of the traditional lecture period and by replacing the lectures with active forms of learning in the classroom ${ }^{[1]}{ }^{[2]}$. Typically, the content is delivered online through recorded lecture videos complemented by textbook and literature reading, browsing websites, and other modes of content delivery ${ }^{[2]}$. Reported advantages of the flipped classroom approach include making the students responsible for their learning and helping them develop lifelong learning skills ${ }^{[3]}$ as well as providing them with individualized instruction to remedy weaknesses or misconceptions ${ }^{[4]}$. Time not spent listening to the lectures is freed to work on additional and more complex applications of the course content, including open-ended design exercises ${ }^{[1]}$. Students work in the classroom in groups and this form of cooperative learning is thought to reinforce their understanding of the course material ${ }^{[2]}$.

Several studies have reported measureable improvements in exam scores and problem solving skills with the flipped classroom ${ }^{[5][1]}$. Other studies found non-significant differences between lecture cohorts and flipped classroom cohorts ${ }^{[2]}$. Students' perceptions of the flipped classroom approach have usually been favorable, but with consistent numbers of students indicating a preference for the traditional lecture format ${ }^{[6]}$. There are questions as to whether the flipped classroom approach can be applied equally well in college classes for less experienced underclassmen and more advanced upperclassmen ${ }^{[1]}$.

We adopted the flipped classroom approach in a freshman-level introductory course and a more advanced medical electronics course of our Biomedical Engineering program and measured students' performance on exams as well as students' perceptions. The data was analyzed to determine if we could detect performance improvements in the two cohorts and how the flipped classroom approach was received by student cohorts at different stages of their college training.

\section{$\underline{\text { 2. Methods }}$}

The flipped classroom model was implemented in two one-semester courses of the undergraduate biomedical engineering curriculum. The first course was a "Medical Electronics" course that is required within the curriculum and is attended in the Spring semester by juniors and seniors within our program. Based on the experience gained in this first course, the flipped classroom was applied the following semester to "Introduction to Biomedical Engineering", a freshman-level course offered in the Fall semester to incoming freshmen.

\subsection{Course Format}

"Medical Electronics" discusses the analysis and design of analog electronic functions commonly found in measurement systems and medical instruments and the devices used to implement these functions in hardware. In particular, students learn about medical transducers and transducer amplifiers, DC power generation and linear power supplies, signal amplification 
with bipolar junction transistors and analog amplifiers, and analog filters. "Introduction to Biomedical Engineering” is an algebra-based course that introduces conservation principles applied to living and man-made systems. In one semester, students learn primarily about conservation of mass and conservation of charge. The students are exposed to the connections between the subjects they learn in basic science courses (chemistry, physics) and engineering applications relevant to Biomedical Engineering. Table 1 below highlights similarities and differences between the two courses as they were taught with the flipped classroom approach.

Table 1: Format of the two courses

\begin{tabular}{|c|c|c|}
\hline & Introduction to BME & Medical Electronics \\
\hline Number of students & $\begin{array}{l}116 \text { in two sections with } \\
\text { separate instructors }\end{array}$ & 47 in one section \\
\hline Student level & Freshmen & Juniors and seniors \\
\hline Mode of delivery & $\begin{array}{c}\text { Video lessons on Learning } \\
\text { Management System }\end{array}$ & $\begin{array}{c}\text { Video lessons on Learning } \\
\text { Management System }\end{array}$ \\
\hline Sample problems in videos & Yes & Yes \\
\hline Preparatory activities & $\begin{array}{c}\text { "Learning checks" scored for } \\
\text { effort }\end{array}$ & $\begin{array}{c}\text { Group quizzes at the } \\
\text { beginning of class }\end{array}$ \\
\hline In-class activities & $\begin{array}{l}\text { Problem-solving exercises, } \\
\text { approximately 50\% from } \\
\text { textbook, 50\% instructor- } \\
\text { generated }\end{array}$ & $\begin{array}{l}\text { Circuit analysis/design } \\
\text { exercises, all instructor- } \\
\text { generated }\end{array}$ \\
\hline Activities format & Group work & Group work \\
\hline Homework & $\begin{array}{l}\text { Yes - textbook and instructor } \\
\text { problems }\end{array}$ & $\begin{array}{c}\text { Yes - textbook and instructor } \\
\text { problems }\end{array}$ \\
\hline Assessment mode & $\begin{array}{l}\text { Quizzes (6) + Midterm (1) + } \\
\text { Final exam }\end{array}$ & $\begin{array}{l}\text { Quizzes (8) + Midterm (1) + } \\
\text { Final exam }\end{array}$ \\
\hline Assessment format & $\begin{array}{l}\text { Multiple-choice problem- } \\
\text { solving questions and short- } \\
\text { answer problems }\end{array}$ & $\begin{array}{l}\text { Multiple-choice problem- } \\
\text { solving questions }\end{array}$ \\
\hline
\end{tabular}

As table 1 illustrates, the implementation was fairly similar between the two courses. The "Introduction to BME" course was divided in two sections to accommodate the number of registered students and both sections had approximately the same number of students. One of the two instructors for this course was also the instructor for the "Medical Electronics" course. For both courses, the instructors prepared Powerpoint presentations of course content, which were narrated and presented in video format using Camtasia Studio (Techsmith). The Powerpoint presentations included sample problems, of which about half were followed by a detailed presentation of the solution while the other half were left for the students to solve on their own. Both the video lessons and the Powerpoint presentations were posted on the Learning Management System Blackboard.

Students in the "Introduction to BME" course completed "Learning checks" comprising a few exercises and conceptual questions to test their understanding of the video lessons they had watched. The learning checks motivated the students to watch the lessons and allowed the instructors to spot misunderstandings in the content presented in the video lessons. Seven 
learning checks were used in the semester, approximately one every other week. Most students completed the learning checks even though these were not scored and not counted in the course grade. In the "Medical Electronics" course, group quizzes were used instead. The group quizzes also comprised conceptual questions and problem-solving exercises but they were solved by the students in groups of 3 to 6 students, with each group completing one response sheet. After the allotted time expired, the groups exchanged their response sheets for scoring. The questions were discussed with the whole class and the student groups marked the answers on the response sheets. The group or groups with the highest number of correct answers were declared "the winners" and received a token prize, usually a bonus point on the next individual quiz. While not having the same level of accountability as the "Learning checks" in the introductory course, the group quizzes in the advanced course resulted in playful challenges between student groups.

Classroom time was spent solving problems in groups for both classes with the instructor and one teaching assistant roaming among the groups and guiding them toward the solution when necessary. When an interesting point, a misunderstanding, or an original solution was identified with one group that warranted mention to the whole class, the instructor discussed it with all the students before resuming the problem-solving exercises. For each problem, the solution was discussed either briefly or in detail after the groups had been able to complete or approach the solution. For the "Introduction to BME" course, the problems originated either from the textbook or were prepared by the instructors while for the "Medical Electronics" course, the instructor generated nearly all the problems as the students tended to not carry their textbook to class.

Traditional homework was assigned in both courses after the course material had been presented through the video lessons and discussed in class through the activities. The amount of homework was approximately $40 \%$ that assigned in previous years when traditional lecture format was used ( $\sim 2$ problems/week vs. 5 problems/week)

\subsection{Assessment of flipped classroom approach}

Three instruments were used to measure the effect of the flipped classroom approach in comparison with the traditional lecture approach: 1) quantitative comparison of performance on exams; 2) a student survey with questions on the student experience; 3 ) end-of-semester course evaluations.

\subsubsection{Comparison of performance on exams}

Student learning and problem solving ability on course-related topics measured by scores on exam questions was compared for the flipped classroom year and the preceding traditional lecture years.

For the Introductory course, the final exam included 7 multiple-choice problem-solving questions (out of a total of 13) and 2 short-answer problems (out of a total of 3) that had been used in the previous offering of the course with the lecture format. Because the point value assigned to the multiple choice questions was slightly different in the two offerings of the course, the marks obtained by each student on these 7 questions and 2 problems was added and scaled to a maximum score of 20. For the electronics course, the final exam included 20 multiple-choice 
problem-solving questions (out of a total of 32) that had been used on the final exams for two preceding offerings of the course with the traditional lecture format. The marks on these questions were added resulting in a total score out of 20.

For both courses, the exam scores were compared for the flipped classroom offering and the traditional lecture offerings using an unpaired t-test to examine if there was a significant difference in performance between the 2 instructional approaches. The exam scores were regrouped in categories corresponding approximately to the A, B, C, D ratings (A: 18-20, B: 15$17, \mathrm{C}: 12-14, \mathrm{D}:<12)$. Two-way contingency analysis and a $\chi^{2}$ test were used to examine if the score distributions were different. In addition, for the electronics course, the exam questions were regrouped by topic and student performance was compared for questions on the same topic using an unpaired t-test. All analyses were carried out with SPSS (14.0).

\subsubsection{Course survey}

An instructor-generated anonymous survey was administered electronically to the students a few weeks before the end of the semester during the flipped classroom year to gather feedback about various aspects of the course, including the video lessons, the in-class activities, and the assessment approach. In addition to ratings, comment fields were included for several survey questions. The survey of the introductory course was an updated version of the survey used for the electronics course with a few additional questions.

\subsubsection{End-of-semester course evaluations}

For both courses, students completed end-of-semester course evaluations mandated by the University. All the questions were answered on a 1-5 Likert scale with 5 being highest. In addition to two global evaluation questions ("Overall, how would you rate this instructor?" and "Overall, how would you rate this course?"), the students rated the course and the instructor on 10 focused aspects of their experience. The student response rate to these surveys was approximately 60-70\%.

The student responses obtained for the flipped classroom offering of the courses were compared to the responses obtained during the 6 previous years when the traditional lecture + discussion format was used using a one sample t-test. For both courses, the evaluation data were obtained for the same instructor teaching the course in the traditional format and in the flipped classroom format.

\section{Results}

\subsection{Exam performance}

\subsubsection{Overall scores}

For the introductory course, the final exam scores of 57 students from the flipped classroom year were compared to the scores of 47 students from the preceding traditional lecture year. For the Electronics course, the final exam scores of 47 students from the flipped classroom year were 
compared to the scores of 87 students from the two previous lecture years. For the introductory course, the average final score in the flipped classroom year was below that observed in the lecture year (Table 2). The converse was observed for the electronics course, for which the final score in the flipped classroom year was markedly higher than that observed when the course was offered in the traditional lecture format.

Table 2: final exam scores for the two courses and the two instructional methods

\begin{tabular}{|l|c|c|c|c|}
\hline Course & Flipped & Traditional & t-stat & P value \\
\hline Introductory & $16.6 \pm 2.6$ & $18.1 \pm 1.7$ & 3.6 & 0.001 \\
\hline Electronics & $16.1 \pm 3.5$ & $14.4 \pm 3.5$ & 2.7 & 0.007 \\
\hline
\end{tabular}

\subsubsection{Distribution of scores}

Figure 1 shows the distributions of exam scores for the two courses and two instructional approaches. For the introductory course, the distributions of exam scores were negatively skewed for both years with a higher frequency of scores in the 18-20 range in the traditional lecture year. The distribution of scores was also negatively skewed in the electronics course for the flipped classroom year. However, the exam scores for the traditional lecture version of the electronics course were more evenly distributed over the whole range. For both courses, contingency analysis revealed significant differences between scores distributions in the traditional lecture year and in the flipped classroom year $(p<0.01)$.
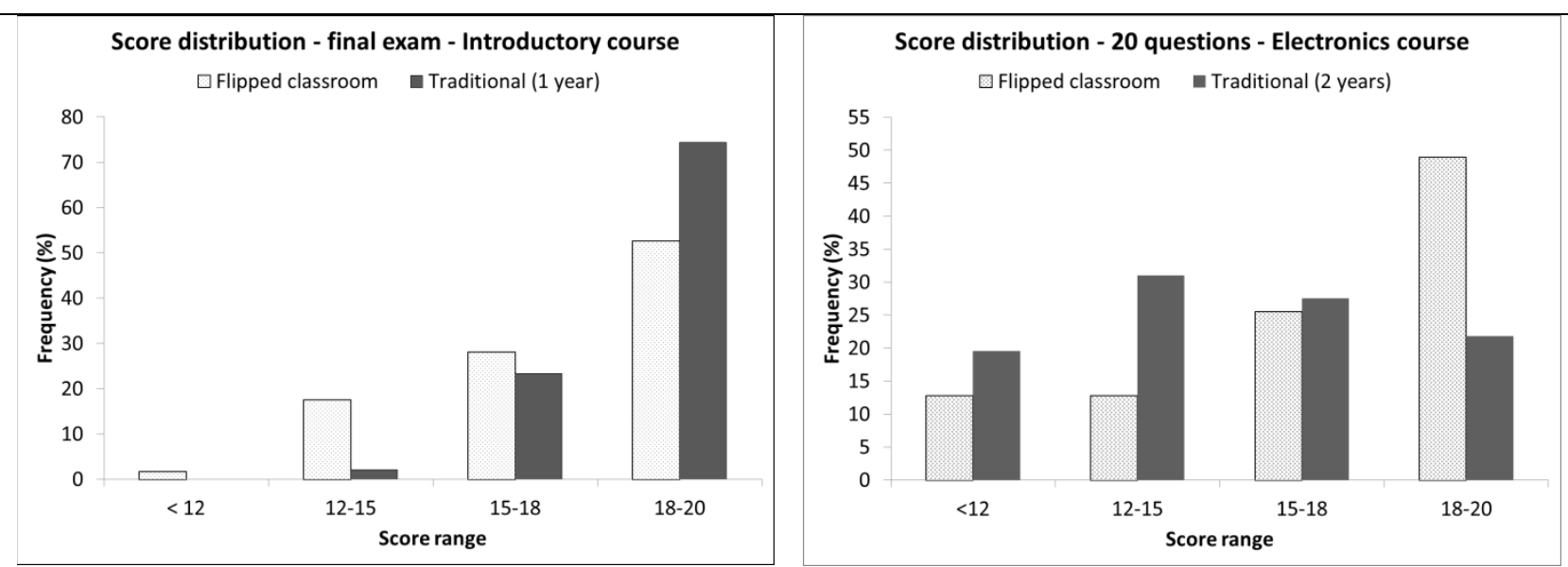

Figure 1: distribution of scores on the final exams of the two courses

\subsubsection{Comparison by topic for electronics course}

Table 3 summarizes the student scores for the exam questions regrouped by topic arranged in the order in which these were discussed during the semester. Average scores in the flipped classroom were higher for all topics with significant differences observed on the first two topics. Variability as measured by the standard deviation was smaller on these two topics. It is possible that the flipped classroom students had better recollection of the topics presented earlier in the semester because they had more practice and thus were able to perform at a higher level and more uniformly at the end of the semester. 
Table 3: scores on final exam questions regrouped by topic for the flipped classroom $(\mathrm{N}=47)$ and the lecture classroom $(\mathrm{N}=87)$. Data presented as Mean score $\pm \mathrm{SD}$

\begin{tabular}{|l|c|c|c|c|}
\hline Topic & \# Questions & Score Flipped & Score Lecture & p value \\
\hline DC pn and Zener diodes & 4 & $3.4 \pm 1.0$ & $2.6 \pm 1.2$ & $<0.001$ \\
\hline Diode rectifiers & 2 & $1.8 \pm 0.4$ & $1.4 \pm 0.6$ & $<0.001$ \\
\hline DC and ac transistors & 6 & $5.9 \pm 1.4$ & $5.4 \pm 1.6$ & NS \\
\hline Analog amplifiers & 4 & $3.1 \pm 1.1$ & $3.1 \pm 1.0$ & NS \\
\hline Comparators & 3 & $1.9 \pm 0.9$ & $1.8 \pm 1.0$ & NS \\
\hline
\end{tabular}

\subsection{Student Survey}

The response rates to the student survey were comparable for the two courses: 50 out of 116 for the Introductory course and 25 out of 47 for the Medical Electronics course. Responses to some of the questions are summarized in table 4 below.

Table 4: Responses to student survey. NA indicates the question was not in the survey

\begin{tabular}{|c|c|c|}
\hline Question & Intro to BME & Med. Electronics \\
\hline \multicolumn{3}{|c|}{$\begin{array}{l}\text { Video lesson questions } \\
\end{array}$} \\
\hline What percentage of video lessons have you watched? & $77 \%$ & $77 \%$ \\
\hline Did you find the videos clear? & Yes: $80 \%$ & Yes: $100 \%$ \\
\hline Did the videos help you learn the class material? & Yes: $72 \%$ & Yes: 96\% \\
\hline \multicolumn{3}{|c|}{ Preparation quiz questions } \\
\hline What percentage of learning checks did you complete? & $95 \%$ & NA \\
\hline Would you prefer if a learning check for every lesson? & Yes: $43 \%$ & NA \\
\hline Did you find the group quizzes useful & NA & Yes: $67 \%$ \\
\hline \multicolumn{3}{|l|}{ In-class activities questions } \\
\hline $\begin{array}{l}\text { Did you find the class activities helpful to complement } \\
\text { readings and video lessons? }\end{array}$ & Yes: $60 \%$ & NA \\
\hline $\begin{array}{l}\text { Did you enjoy the activities as implemented or would } \\
\text { you prefer a more structured classroom? }\end{array}$ & As is: $18 \%$ & NA \\
\hline $\begin{array}{l}\text { Was there another type of in-class activity you would } \\
\text { have liked? }\end{array}$ & Yes: $49 \%$ & Yes: $25 \%$ \\
\hline $\begin{array}{l}\text { Did you find it effective to have the instructor and } \\
\text { teaching assistant work with individual student groups? }\end{array}$ & Yes: $72 \%$ & NA \\
\hline Optimal amount of time to spend on each activity? & NA & 11-20 min: $58 \%$ \\
\hline \multicolumn{3}{|l|}{ Homework questions } \\
\hline Did the homework help you synthesize your learning? & Yes: $84 \%$ & Yes: 96\% \\
\hline Was the amount of homework appropriate? & Yes: $74 \%$ & Yes: $88 \%$ \\
\hline
\end{tabular}

The video lessons were well received by the two groups of students who reported watching most of them. Students from the Introductory course reported completing 95\% of the learning checks which was confirmed by the actual number of samples collected in the semester.

Sixty percent of these students found the in-class activities helpful and commented that the activities helped clarify the videos and deepen their understanding of the topics. However, about 
half of Introductory course students reported they would have preferred a different type of activity, while this was the case only for $25 \%$ of the students in the Electronics course. A large number of students in the Introductory course indicated they would have preferred more lecturing or a short lecture before the activities. Both groups of students found the traditional homework useful.

In their free comments, some students in the Introductory course indicated that the course was challenging and presented many aspects of the sciences and fundamental aspects of BME while others reported the material was elementary or too easy. The ability to focus in the flipped classroom setting which is noisier because of the conversations between groups was quoted by several students as a distraction. This complaint was never mentioned by the students of the Medical electronics course where the noise level due to multiple conversations was qualitatively similar.

\subsection{Course evaluation}

The student ratings in the end-of semester course evaluation are traditionally lower for the freshman-level Introduction to Biomedical Engineering course than the ratings observed in other courses. In part, the freshmen begin college with different expectations about what biomedical engineering is. In addition, they have a limited basis for comparison between college courses. This was also the case for the 2014 flipped classroom year. In particular, student responses to the overall instructor ratings were not different from those observed when the course was offered in the traditional lecture mode (Fig. 2). For the Medical Electronics course, the overall instructor rating was significantly higher with the flipped classroom. For both courses, the overall course rating remained in the range observed with the lecture mode (Introductory course: 3.2 in flipped classroom year vs. $3.3 \pm 0.1$ for lecture years; Electronics course: 4.3 in flipped classroom year vs. $4.1 \pm 0.3$ for lecture years).

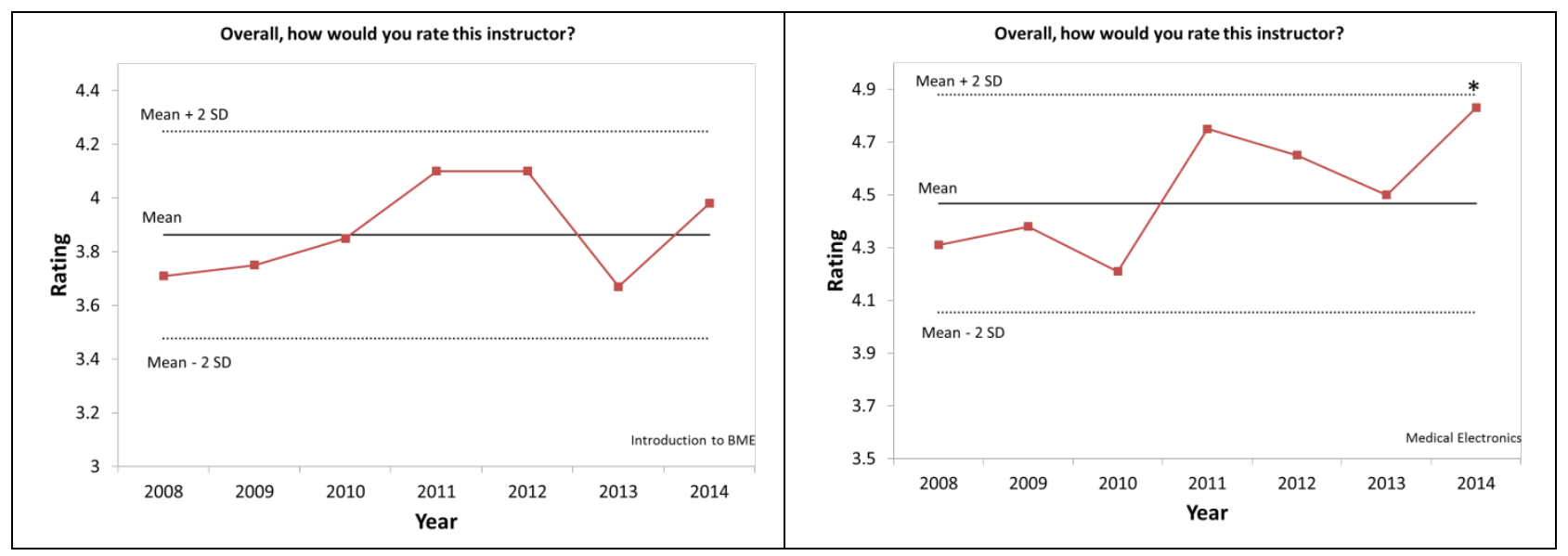

Figure 2: Ratings in flipped classroom year (2014) and 6 preceding lecture years in response to evaluation question: "How would you rate this instructor?"

In general, the student ratings on the focused questions were not significantly different for the flipped classroom year in the introductory course while the ratings were increased in the 
electronics course suggesting more enthusiasm for the flipped classroom in the electronics course.

Two questions showed a significant upward jump for both courses in the 2014 flipped classroom year. Students' responses to the question "The instructor encouraged students to participate in their own learning” were significantly higher (Fig. 3). In fact, the magnitude of the change was larger for the introductory course and indicated a substantial difference compared to the year-toyear fluctuations observed in the lecture years. Likewise, the responses to the question "The instructor was enthusiastic about communicating the subject matter" were increased compared to the year-to-year average for both courses (Fig. 4).

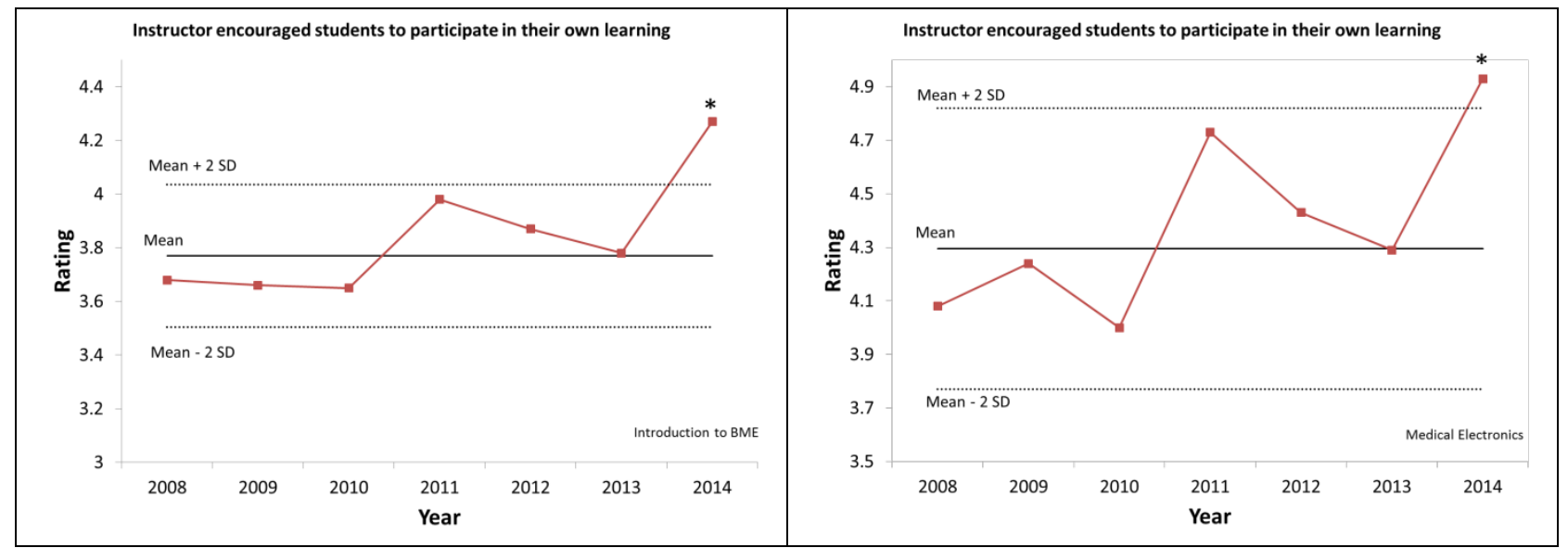

Figure 3: Ratings in flipped classroom year (2014) and 6 preceding lecture years in response to evaluation statement: “The instructor encouraged students to participate in their own learning?”

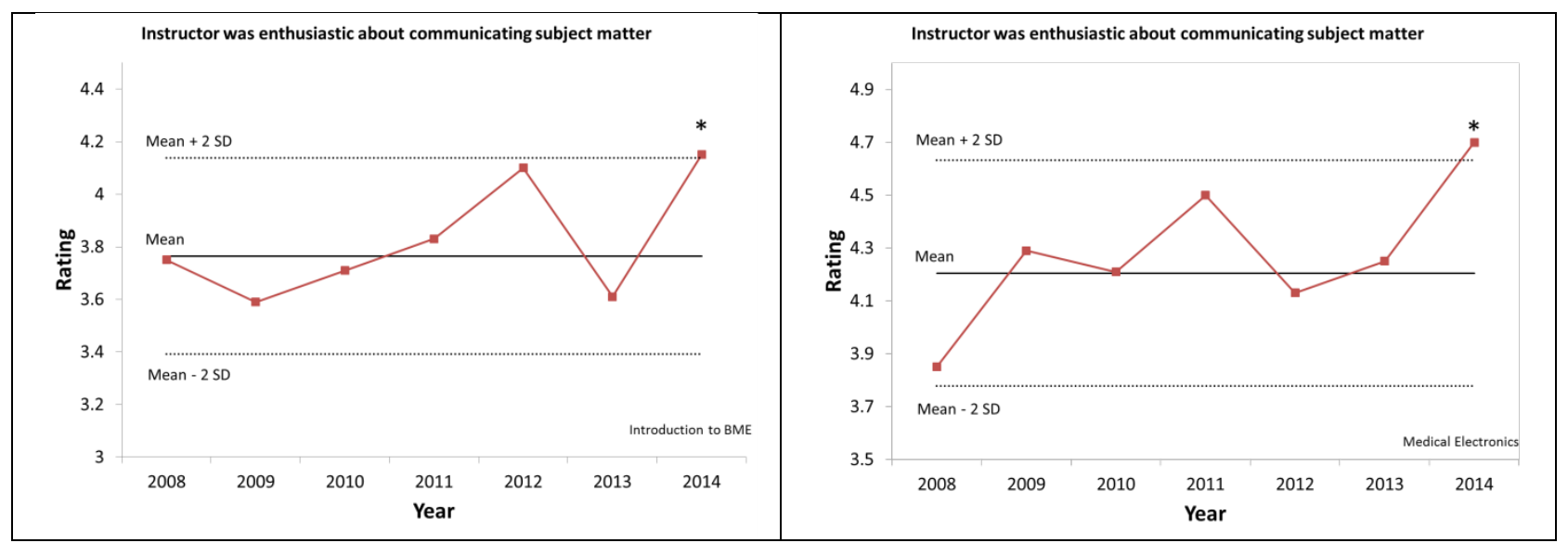

Figure 4: Ratings in flipped classroom year (2014) and 6 preceding lecture years in response to evaluation statement: "The instructor was enthusiastic about communicating the subject matter?"

In their free-response comments, nearly half of the respondents indicated they would have preferred a more traditional lecture approach for the Introductory course, whereas this occurred only a few times for the medical electronics course. These results are in agreement with the responses noted in the student survey. 


\section{Discussion}

The results of this study may be surprising in that a similar implementation of the flipped classroom model in two courses was better accepted by students in the Medical Electronics course than it was in the Introduction to Biomedical Engineering course. Exam performance improved markedly for the first course while it declined for the second course when compared to performance in a conventional lecture classroom. Yet both cohorts reported watching the video lectures to the same extent and found equivalent amounts of homework equally helpful to solidify their understanding of the course content.

Comparison of objective student performance in a flipped classroom and a traditional lecture setting has been reported in a small number of studies of undergraduate engineering and science cohorts for semester-long interventions ${ }^{[5]}{ }^{[2]}$. In a senior-level course on user-interface design taught concurrently to 2 sections with the flipped classroom and the traditional approach, exam scores were found to be marginally higher and overall performance on assignments was significantly higher for the flipped classroom group ${ }^{[5]}$. A study of a senior-level mechanical engineering course structured like our study over two consecutive years also revealed better exam performance for the flipped classroom cohort on certain course topics ${ }^{[1]}$. Student performance was equivalent in the two cohorts in a sophomore-level numerical methods course [2].

A near endless number of variants can be imagined for electronic circuits even for an introductory analog electronics course dealing with a limited number of devices and functions. Thus the ability to analyze new circuits becomes essential to succeed at problem-solving even for closed set exam problems. Learning a few standard solutions by watching the instructor solve a small number of problems and through a limited amount of homework practice in a traditional lecture format may be insufficient to learn to analyze circuits not seen before. Practicing circuit analysis and problem solving intensely for one semester would have provided the flipped classroom students with enough practice to solve many more circuit problems related to the course content. This could explain the higher scores in the flipped Electronics course compared to the lecture version and a final exam distribution of scores skewed toward the " $\mathrm{A}$ " grade in the flipped classroom and more evenly distributed over the " $\mathrm{A}-\mathrm{D}$ " range for the conventional lecture format. The higher exam scores observed for the flipped classroom cohort originated mostly from certain types of exam questions (Table 3) as was observed by others ${ }^{[1]}$. In our study, the corresponding topics were those learned in the first part of the semester perhaps because the additional problem-solving practice and the frequent quizzes helped the flipped classroom students learn and recall this material better.

In contrast, for the Introductory course, the set of possible exam problems and questions was more limited and many exam questions, which by nature of the study design originated from the lecture offering of the course, would have resembled problems first solved in class and then revisited in homework by the "lecture" cohort. Thus, the "lecture" students were prepared to solve these problems and performed at a very high level on their exams ( $>70 \%$ in "A" range). More problems were attempted and covered in the flipped classroom setting, but this abundance of problems could have created confusion among some students when preparing for the final exam and led to lower exam scores. Thus, a limitation of the study design (comparison of 
performance on exam questions from the lecture offering) coupled with the nature of the course content could explain the observed performance differences between the two courses.

The flipped classroom approach transfers the responsibility of learning the course content away from the instructor and toward the students while helping them practice the skill to learn on their own ${ }^{[3]}$. This feature was recognized by the students in both courses, and more acutely so in the Introductory course as indicated in the course evaluations (Fig. 3). It is possible that a substantial number of students in that course (mostly freshmen) were not accustomed to being in charge of their learning and as a result would have viewed the flipped classroom model to be less desirable than the lecture model. The juniors and seniors in the Electronics course, being comfortable learning on their own, would have been more willing to accept this responsibility and in this way easily adapted to the flipped classroom approach. Difficulty to adapt to the flipped classroom approach has been reported in other studies of introductory and underclassmen courses $^{[6]}[2]$.

Strayer ${ }^{[6]}$ analyzed the perceptions of students toward learning activities in a flipped classroom environment. The approach of some students was summarized by "I want you to show me" while others preferred to "struggle through and only ask questions when they were stuck". Interestingly, a good number of students of the Introductory course stated in their course evaluations that they would have preferred to have the instructor solve a few problems at the board before attempting the problem-solving activities with their groups. It is possible that the freshmen of the Introductory course were not ready for the looser structure of the flipped classroom, the noisier classroom environment, and the onus of having to learn the course content ahead of time. However, the flipped classroom has been very successful in high school science courses ${ }^{[4]}$ with younger students than the freshmen of our study. Thus, it is more likely that inhomogeneity in prior preparation and in expectations toward teaching and learning among first-year college students coming from different high schools could have affected their perceptions of the course and of the instructional method. In such circumstances, it may be preferable to offer a brief "power" lecture at the beginning of the classroom meeting to homogenize the knowledge level of the students and increase the comfort level of some students who need additional guidance.

Exam performance on problem-solving multiple choice questions or closed ended problems only captures limited aspects of learning and does not capture other valuable engineering skills that map to the ABET student outcomes such as the ability to work in teams (outcome d) or the ability to engage in lifelong learning (outcome i) ${ }^{[3]}$. In as much as the flipped classroom systematically exposes students to group work for several hours every week in the classroom and trains them to learn on their own through the video lectures, the approach can help students better develop as future engineers while also helping engineering programs to satisfy accreditation requirements.

Among the limitations of the study, the comparison between conventional lecture format and flipped classroom format was done on relatively small groups of students with a single year of experience for the flipped classroom. While the instructors were used to having students work on problems in the classroom even in the lecture offering of the courses, this was their first experience with fully flipped courses. 


\section{Bibliography}

1 Mason GS, Rutar Shuman T, Cook KE. Comparing the effectiveness of an inverted classroom to a traditional classroom in an upper-division engineering course. IEEE Transactions on Education. 2013;56(4):430-435.

2 Bishop JL. A controlled study of the flipped classroom with numerical methods for engineers. PhD Dissertation. Logan, Utah: Utah State University; 2013.

3 Felder RM, Brent R. Designing and teaching courses to satisfy the ABET engineering criteria. Journal of Engineering Education. 2003;92(1):7-25.

4 Bergmann J, Sams A. Flip your classroom: reach every student in every class every day. International Society for Technology in Education; 2012.

5 Day JA, Foley JD. Evaluating a web lecture intervention in a human-computer interaction course. IEEE transactions on education. 2006;49(4):420-431.

6 Strayer JF. The effects of the classroom flip on the learning environment: a comparison of learning activity in a traditional classroom and a flip classroom that used an intelligent tutoring system. PhD Dissertation. Columbus: Ohio State University; 2007. 